\title{
Guanidinium Nitrate/Silica Sulfuric Acid/Ammonium Bromide as an Effective, Viable and Metal-free Catalytic Media for the Selective Oxidation of Sulfides to the Sulfoxides
}

\author{
Mohsen Nikoorazm, Arash Ghorbani-Choghamarani, and Hamid Goudarziafshar \\ Department of Chemistry. Faculty of Science, Ilam Cniversin. P. O. Box 69315516. 1/am. Iran \\ E-mail: e nikoorazmatahoo.com \\ Received September If, 2009. Accepted October 27, 2009
}

Key Words: Sulfide, Sulfoxide. Guanidinium nitrate, Ammonium bronude, Silica sulfuric acid

In the last few years. heterogeneous systems ${ }^{1-4}$ has become increasingly used in organic synthesis. mainly because the reactions are carried out under mild conditions and the organic products are easily isolated from the reaction media. In addition, the stability and cheapness. high yields of the products. short reaction times. and reusability is other important advantages of these systems.

Chemoselective oxidation of sulfides to sulfoxides is an important synthetic method because corresponding sulfoxides are valuable sy nthetic intermediates for the synthesis of chemically and biologically significant molecules. ${ }^{6.8}$ Sulfoxides are also valuable in $\mathrm{C}-\mathrm{C}$ bond-forming ${ }^{9.16}$ and molecular rearrangements. ${ }^{11.13}$ Even though various approaches have been reported for the oxidation of sulfides to sulfoxides such as $\mathrm{H}_{2} \mathrm{O}_{3}$ iron(III)-salen, ${ }^{1+}$ tert-butyl hydroperoxide/Ti( $(\mathrm{PrO}) / 1.2$-diphenylethane-1,2-diol, ${ }^{15} \mathrm{TaCl}_{3} / \mathrm{H}_{2} \mathrm{O}_{-},{ }^{16}$ sodium perborate or sodium percarbonate/silica sulfuric acid/KBr. 3 -carboxypy ridinium chlorochromate/ $\mathrm{AlCl}_{3},{ }^{18} \mathrm{ZrCl}_{4} / \mathrm{H}_{2} \mathrm{O}_{2}$. ${ }^{19}$ ceric ammonium nitrate (CAN) supported on silica/ $\mathrm{NaBrO}_{3}{ }^{20} \mathrm{H}_{2} \mathrm{O}_{2}$ $\mathrm{N}$-hydroxysuccinimide, ${ }^{?]}$ these methods suffer from some disadvantages like long reaction times. expensive reagents and catalysts. contamination of metallic reagents. difficulties in isolation of products, and formation of over-oxidation products.

In order to improve above-mentioned limitations and in continuation of our ongoing programs to introduce new reagents we became interested to apply a new catalytic method for the conversion of sulfides to the sulfoxides. Recently we have published a few reports on the oxidation of sulfides to the sulfoxides ria in situ generation of bromonium ion $\left(\mathrm{Br}^{-}\right)$. which is produce by treatment of metal nitrate or nitrite in the presence of an acidic source ${ }^{2-2}$ Therefore herein we decided to introduce a metal-free media for the production of bromonium ion $\left(\mathrm{Br}^{+}\right)$for the selective oxidation of sulfides to the sulfoxides by guanidinium nitrate. silica sulfuric acid and catalytic amounts of ammonium bromide in the presence of wet $\mathrm{SiO}_{2}(50 \%$

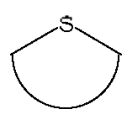

1

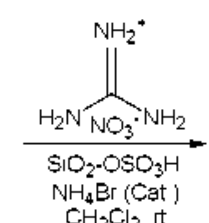

$\mathrm{CH}_{2} \mathrm{Cl}_{2}$, $\mathrm{t}$

Scheme 1 w/w). Consequently, a variety of aliphatic and aromatic sulfides 1 were subjected to the oxidation reaction to the corresponding sulfoxides 2 using guanidinium nitrate $\mathbf{I}$ silica sulfuric acid II and catalytic amounts of $\mathrm{NH}_{4} \mathrm{Br}$ III in the presence of wet $\mathrm{SiO}_{2}(50 \% \mathrm{w} / \mathrm{w})$ in dichloromethane at room temperature with good to moderate yields (Scheme 1 and Table 1).

Sulfoxidation reaction has been heterogeneously performed under mild conditions. All reagents and catalyst are insoluble in the reaction solvent. Consequently, sulfoxides easily produced via miving of a sulfide. guanidinium nitrate. silica sulfuric acid, wet $\mathrm{SiO}_{2}$ and a $5 \%$ mol of anmonium bromide; then stirring of this mixture at room temperature. Pure products can be easily isolated from the reaction media by washing the reaction mixture with dichloromethane. simple filtration and evaporation of dichloromethane.

As is evident from Table 1 the good range of tum over number (TON). (i.e. 5.40 to 19.60) of ammonium nitrate as cataly st is observed. To investigate the catalytic role of $\mathrm{NH}_{4} \mathrm{Br}$. as catalyst. 4-chlorophenyl methyl sulfide was subjected to the oxidation reaction in the absence of this agent as standard model. Surprisingly: 4-chlorophenyl methyl sulfoxide was obtained only in $7 \%$ yield after 24 hours (Table 1 , entry 4). Also to show the role of silica sulfuric acid as acidic source of this procedure. same sulfide was subjected to sulfoxidation in the absence of acid. Interestingly, no sulfoside product was observed after $24 \mathrm{~h}$ (Table 1 , entry 5 ).

To consider chemoselectivity in the described system allyl methyl sulfide was converted successfully to allyl methyl sulfoxide in $85 \%$ yield and carbon-carbon double bond was intact in the course of reaction (Table l. entry 16).

In order to investigate more selectivity of our system thianthrene was homoselectively oxidized to the thianthrene mono sulfoxide that is only one sulfur moiety took place in the sulfoxidation reaction.

\section{Experimental Section}

General. Chemicals were purchased on Fluka. Merck and Aldrich chemical companies. The oxidation products were characterized by comparison of their spectral (IR. ' $H$ NMR, or ${ }^{13} \mathrm{C}$ NMR) and physical data with authentic samples.

Oxidation of t-chlorophenyl methyl sulfide to t-chlorophenyl methyl sulfoxide by guanidinium nitrate and silica 
Table 1. Oxidation of sultides $\mathbf{1}$ to the corresponding sulfoxides 2 using guanidinium nitrate $\mathbf{L}$ silica sulfuric acid $\mathbf{I I}$ and catalytic amounts of $\mathrm{NH}_{4} \mathrm{Br}$ III in the presence of $\mathrm{wet}^{\mathrm{SiO}}(50 \% \mathrm{w} / \mathrm{w})$ in dichloromethane at room temperature

\begin{tabular}{|c|c|c|c|c|c|c|c|c|}
\hline \multirow{2}{*}{ Entry } & \multirow{2}{*}{ Substrate } & \multirow{2}{*}{ Product } & \multicolumn{3}{|c|}{ Substrate/Reagents/Catalyst ${ }^{a}$} & \multirow{2}{*}{ Time (Min) } & \multirow{2}{*}{ Yield $(\%)^{b}$} & \multirow{2}{*}{ TON } \\
\hline & & & I & II & III & & & \\
\hline 1 & & & 2 & 0.3 & 0.05 & 60 & 80 & 16.0 \\
\hline 2 & & & 2 & 0.3 & 0.05 & 50 & 97 & 19.4 \\
\hline 3 & & & 2 & 0.3 & 0.05 & 45 & 97 & 19.4 \\
\hline 4 & & & 2 & 0.3 & - & $24 h$ & $7^{\circ}$ & - \\
\hline 5 & & & 2 & - & 0.05 & $24 h$ & No reaction & - \\
\hline 6 & & & 2 & 0.3 & 0.05 & 45 & 92 & 18.4 \\
\hline 7 & & & 2 & 0.3 & 0.05 & 70 & 93 & 18.6 \\
\hline 8 & & & 2 & 0.3 & 0.05 & 55 & 82 & 16.4 \\
\hline 9 & & & 2 & 0.4 & 0.05 & $19 \mathrm{~h}$ & 98 & 19.6 \\
\hline 10 & & & 2 & 0.3 & 0.05 & 140 & 96 & 19.2 \\
\hline 11 & & & 2 & 0.3 & 0.05 & 55 & 94 & 18.8 \\
\hline 12 & & & 2 & 0.3 & 0.05 & 25 & 27 & 5.4 \\
\hline 13 & C. $\mathrm{H}_{3} \mathrm{SS}_{\mathrm{S}}$ & & 2 & 0.3 & 0.05 & 85 & 97 & 19.4 \\
\hline 14 & & & 2 & 0.3 & 0.05 & 30 & 89 & 17.8 \\
\hline 15 & & & 2 & 0.3 & 0.05 & 30 & 98 & 19.6 \\
\hline 16 & & & 2 & 0.3 & 0.05 & 390 & 85 & 17.0 \\
\hline
\end{tabular}

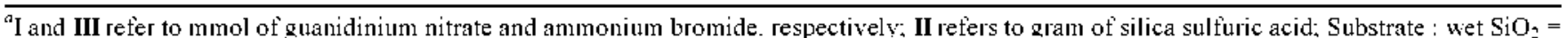
$1 \mathrm{mmol}: 0.2 \mathrm{~g} .{ }^{E}$ Isolated yield. 'Sulfoxide isolated by TLC.

sulfuric acid in the presence of ammonium bomide as catalyst. To a mixture of t-chlorophenyl methyl sulfide $(0.158 \mathrm{~g} .1$ monol). wet $\mathrm{SiO}_{2}(0.2 \mathrm{~g})$, guanidinium nitrate $(0.244 \mathrm{~g} .2$ mmol) and ammonium bromide (0.005 g. $0.05 \mathrm{mmol})$ in $\mathrm{CH}_{2}$ $\mathrm{Cl}_{2}(10 \mathrm{~mL})$, silica sulfuric acid $(0.3 \mathrm{~g})$ was added. The resulting mixture was stirred at room temperature for $45 \mathrm{~min}$ (the reaction progress was monitored by TLC) and then filtered. The residue was washed with $\mathrm{CH}_{2} \mathrm{Cl}_{2}(20 \mathrm{~mL})$. Anhydrous $\mathrm{Na}_{2} \mathrm{SO}_{4}$ ( $3 \mathrm{~g}$ ) was added to the filtrate and filtered off after $20 \mathrm{~min}$. Finally $\mathrm{CH}_{2} \mathrm{Cl}_{2}$ was evaporated and 4-chlorophenyl methyl sulfoxide obtained in $97 \%$ yield $(0.169 \mathrm{~g})$. ${ }^{1} \mathrm{H}-\mathrm{NMR}(200$
$\left.\mathrm{MHz}, \mathrm{CDCl}_{3}\right) \delta 7.47-7.63(\mathrm{dd}, J=1+.0 .8 .6 \mathrm{~Hz}, 4 \mathrm{H}) .2 .75(\mathrm{~s}$ $3 \mathrm{H}){ }^{i 3} \mathrm{C} \mathrm{NMR}\left(50 \mathrm{MHz}, \mathrm{CDCl}_{2}\right) \delta 143.8,137.1,129.5,125.0$. 43.7 .

Selected iepresentative spectral data.

4-Thianthrene mono sulfoxide: ${ }^{\mathrm{H}} \mathrm{H}-\mathrm{NMR}\left(400 \mathrm{MHz}, \mathrm{CD}_{3}\right.$ $\mathrm{SOCD}_{3}$ ) o 7.80-7.84 (m. 2H). 7.65-7.68 (m. lH), 7.55-7.58 (m. $\mathrm{lH}):{ }^{15} \mathrm{C}$ NMR $\left(100 \mathrm{MHz}, \mathrm{CD}_{3} \mathrm{SOCD}_{3}\right)$ oे l+1.2. 130.9, 129.8 . $129.3,128.2 .124 .7$.

Methyl 3-(methylsulfinyl)propanoate: ${ }^{\mathrm{H}} \mathrm{H}-\mathrm{NMR}(90 \mathrm{MHz}$. $\mathrm{CDCl}_{3}$ ) o 3.70 (s. 3H), 3.33 (t. 2H), 2.84-2.91 (n, 5H); IR (KBr) $\bar{v} 1017,1245,1376.1461 .1632 .1734,2855 \mathrm{~cm}^{-1}$. 
Allyl methyl sulfoxide: ' $\mathrm{H}$ NMR $\left(200 \mathrm{MHz}, \mathrm{CD}_{3} \mathrm{SOCD}_{3}\right) \delta$ 5.75-5.97 (m. IH). $5.3 \mathrm{l}-5.39(\mathrm{~m} .2 \mathrm{H}) .3 .34-3.62(\mathrm{~m} .2 \mathrm{H}) .2 .50$ (s. $3 \mathrm{H}):{ }^{13} \mathrm{C}$ NMR $\left(50 \mathrm{MHz}, \mathrm{CD}_{3} \mathrm{SOCD}_{3}\right) \dot{o} 127.5,123.3 .56 .5$. 37.4 .

Acknowledgments. We are grateful to research facilities of Ilam University. Ilam. Iran for financial support of this research project.

\section{References}

1. Tapia, R.; Torres, G.; Valderrama, T. A. Swnthetic Conmun. 1986 , 16,681

2. Gao, Y Lam, Y. Adv. Swhth. Catal. 2008, 350, 2937.

3. Abraham, S.: Rajan, P. K: Sreekmmar, K. Poly .J. 1997, $29,12$.

4. Gondarzian, N.; Ghahramani, P.; Hossini, S. Polvm. Iht. 1996. 39,61 .

5. Shirini, F.; Zolfigol, M. A.; Salehi, P.: Abedini, M. Curr. Org. Chem. 2008, 12,183.

6. Hiroi, K.: Suzuki, Y: Abe, I: Kawagishi, R. Tetrahedron 2000, 56,4701

7. Carreno, M. C. Chem. Rev: $1995,95,1717$.

8. Femandez, I.: Khiar, N. Chem. Rev 2003, 103, 3651.

9. Satoh, T.; Kuramochi, Y.; Inone, Y. Tetrahedron Lett. 1999, 40, 8815 .

10. Kosugi, H.; Watanabe, Y.; Uda, H. Chem. Left. 1989, 1865.

11. Christov, V. C. Ivanov, I. K. Sinthetic Commun. $2004,34,3963$.

12. Aoyagi, S.; Makabe, M.; Shimada, K.: Takikawa, Y: Kabuto, C. Tetrahedron Lett. 2007, 48, 4639 .
13. Shainyan, B. A.; Kirpichenko, S. V.: Freeman, F. J. Am. Chem. Soc. 2004, 126, 11456

14. Jayaseeli, A. M. I.; Rajagopal, S. J. Mol Catal A-Chem. 2009. 309,103 .

15. Jiang, B.; Zhao, X.-L.; Dong, J.-J.; Wang, W--T. Eltr J. Org. Chem. $2009,987$.

16. Kirihara, M.; Yamamoto, J.: Noguchi, T.: Hirai, Y. Tetrahedron Letr. $2009,50,1180$.

17. Habibi, D.; Zolfigol, M. A.; Safaiee, M.; Shamsian, A.; Ghorbani-Choghamarani, A Catal Commm. 2009, 10, 1257.

18. Mohammadpoor-Baltork, I.; Memarian, H. R.: Báhrami, K. Con. J. Chem. 2005, 83, 115.

19. Bahrami, K. Tetwhedron Lett. 2006, 47, 2009

20. Ali, M. H.; Kriedelbangh, D.: Wencewicz, T. Symthesis 2007, 3507.

21. Xiong, Z.-G.: Zhang, J.: Hu, X.-M. Appl. Catal. A-Gen 2008, 334.44

22. Ghorban-Choghamarani, A.; Goudarziafshar, H.; Nikoorazm, M.; Youseti, S. Lett. Oig. Chem. 2009, 6, 335.

23. Zolfigol, M. A.; Amani, K.: Ghorbani-Choghamarani, A.; Hajjami, M.; Ayazi-Nasrabadi, R.; Jafari, S. Catal. Commun. 2008, 9.1739 .

24. Amani, K.: Zolfigol, M. A.: Ghorbani-Choghamarani, A.; Hajiami, M. Monatsh. Chem. 2009, 1+0,65.

25. Zolfigol, M. A.; Amani, K.; Hajjami, M.; Ghorbani-Choghamarani, A. Honatsh. Chem $\mathbf{2 0 0 8}, 139,895$.

26. Ghorbani-Choghamarani, A.; Rezaei, S. J. Chin. Chent. Soc: 2009, 56,251 .

27. Ghorbani-Choghamarani, A.; Goudarziafshar, H.: Hajiami, M.; Soltani, T. J. Chin. Chent Soc. 2008, $55,1191$. 